\title{
Syllidae mitochondrial gene order is unusually variable for Annelida
}

M. Teresa Aguado ${ }^{1}$, Sandy Richter ${ }^{2,6}$, Rebekka Sontowski ${ }^{2,6}$, Anja Golombek ${ }^{3}$, Torsten H. Struck ${ }^{4}$ and Christoph Bleidorn ${ }^{5,6}$

${ }^{1}$ Departamento de Biología, Facultad de Ciencias, Universidad Autónoma de Madrid, Cantoblanco, 28049 Madrid, Spain.

${ }^{2}$ Molecular Evolution and Systematics of Animals, Institute of Biology, University of Leipzig, Talstraße 33, D-04103 Leipzig, Germany.

${ }^{3}$ Zoological Research Museum Alexander Koenig, Adenauerallee 160, D-53113 Bonn, Germany

${ }^{4}$ National Centre for Biosystematics, Natural History Museum, University of Oslo, P.O. Box 1172, Blindern, NO-0318 Oslo, Norway

5 Department of Biodiversity and Evolutionary Biology, Museo Nacional de Ciencias Naturales, Spanish National Research Council (CSIC), José Gutiérrez Abascal 2, 28006 Madrid, Spain

${ }^{6}$ German Centre for Integrative Biodiversity Research (iDiv) Halle-Jena-Leipzig, Deutscher Platz 5e, 04103 Leipzig, Germany

Corresponding author: M. Teresa Aguado, e-mail: maite.aguado@uam.es 


\section{Abstract}

Complete mitochondrial genomes of five syllids (Streptosyllis sp., Eusyllis blomstrandi, Myrianida brachycephala, Typosyllis antoni and Typosyllis sp.) have been obtained using Illumina sequencing. Together with two previous studied taxa (Ramisyllis multicaudata and Trypanobia cryptica), the analysed sequences represent most of the main lineages within the family Syllidae (Anoplosyllinae, Eusyllinae, Autolytinae and Syllinae). The genomic features, gene order and phylogenetic relationships are examined. Unusual for annelids, syllid mitochondrial genomes are highly variable in their gene order. Considering genomic features, such as length, skewness, gene content, and codon bias, most similar to the rest of annelids are the genomes of E. blomstrandi and M. brachycephala, while Streptosyllis sp. and the analysed sylline taxa (R. multicaudata, T. cryptica, T. antoni and Typosyllis sp.) are the most dissimilar. Two methionine tRNA's (trnM) have been found in T. antoni and Typosyllis $\mathrm{sp}$. The $\mathrm{mt}$ genomes of these latter taxa are the longest with numerous non-coding regions. The 13 protein coding genes, as well as the rRNA's are used to perform phylogenetic analyses that recovered the relationships within the family explored before by previous authors. The gene order in Syllidae shows very different patterns. E. blomstrandi and $M$. prolifera show a similar pattern to the one found in Pleistoannelida; however this might have changed at least twice within Syllidae: in Streptosyllis sp. and within Syllinae. All analysed Syllinae show different gene order, thereby illustrating more variability as all other pleistoannelids analysed so far. The information provided herein allows a more accurate reconstruction of the possible evolutionary scenarios in Syllidae.

Key words: Anoplosyllinae, Autolytinae, Eusyllinae, mitochondrial genome, phylogeny, Syllinae

\section{Introduction}

Animal mitochondrial $(\mathrm{mt})$ genomes are circular duplex molecules of DNA that usually contain 13 protein coding genes, 22 tRNA's and two rRNA's (Boore 1999). The analysis of the 
sequences and the order in which these genes are organized provide valuable information that has been widely used to resolve phylogenetic relationships of different taxa at different levels (Vallès and Boore 2006). The $\mathrm{mt}$ genomes have been shown to be quite suitable for younger divergences, though less informative for deep phylogenies (Bernt et al. 2013a). Within Annelida, comparatively few analyses dealing with complete mt genomes were published during the first decade of the 2000s (e.g., Boore 2004; Jennings and Halanych 2005; Bleidorn et al. 2006; Vallès and Boore 2006; Zhong et al. 2008; Mwinyi et al. 2009; Shen et al. 2009). By using next-generation sequencing technology the generation of $\mathrm{mt}$ genomes became more feasible and less time intensive. Including the here newly published sequences, 89 complete annelid mt genomes were available in April 2016 (Supplementary Table 1). However, whereas there are a high number of genomes available for Glyceridae, Clitellata and Siboglinidae (Li et al. 2015; Richter et al. 2015; Zhang et al. 2016), most other annelid taxa are less well represented. Based on the available data, the arrangement of genes in Annelida was considered as highly conserved. Moreover, most of the available mt genomes belong to one of the two major groups within annelids: Errantia or Sedentaria, that together form the large clade Pleistoannelida (Struck 2011). Recently, Weigert et al. (2016) included several basal branching annelids and found that the gene order was more variable than expected. The common pattern previously assigned to Annelida could be considered as the ground pattern in Pleistoannelida, while the basal branching groups showed a completely different arrangement of genes. Within Pleistoannelida, a taxon which origin dates back to the late Cambrian - Early Ordovician (Hints and Eriksson 2007; Weigert and Bleidorn 2016), the order of protein coding and ribosomal genes is highly conserved, with the Echiura, Ampharetidae and Diurodrilus as the only exceptions (Boore 2004; Wu et al. 2009; Zhong et al. 2011; Golombek et al. 2013). All these three taxa belong to Sedentaria.

Aguado et al. (2015a) analysed the first two $\mathrm{mt}$ genomes of Syllidae, one of the largest groups not only in Errantia, but in Annelida in general. The Syllidae currently comprises more than $700 \mathrm{spp}$. that inhabit practically all marine benthic realms (Aguado et al. 2015b). Surprisingly, Aguado et al. (2015a) found that the gene order of the two investigated syllids (Ramisyllis multicaudata and Trypanobia cryptica) was completely different from the ground pattern proposed for Pleistoannelida. However, since these were the first two mt genomes from syllids, the authors could not assess if Syllidae in general or only members of the more recent clade including Ramisyllis and Trypanobia show these different gene orders. 
The phylogenetic relationships within Syllidae were initially studied including few taxa (Licher 1999; Nygren 1999; Nygren and Sundberg 2003) or focusing on sub-taxa (i.e. Typosyllis by Licher (1999) and Autolytinae by Nygren (2004)). Some years later Aguado et al. (2007) performed a more comprehensive study including molecular information (the nuclear gene $18 S$ and the mitochondrial $r r n L$ and cox1) from a larger amount of taxa (88 terminals). Aguado et al. (2012) included molecules (same genes) and morphology of 213 terminals. More recently, Aguado et al. (2015a; 2015b) performed new molecular analyses, including more terminals when compared with previous studies (genera Alcyonosyllis, Trypanobia and Ramisyllis). All analyses agreed in recovering the family Syllidae as monophyletic, early divided into two major clades: one corresponding to the subfamily Anoplosyllinae and the other one comprising the rest of syllids. Within the second one, the traditional subfamilies were found to be monophyletic: Autolytinae, Exogoninae, Syllinae, and Eusyllinae. The latter has been reorganized by Aguado et al. (2012). Some genera could not be assigned to any of these subfamilies and are currently considered as independent groups (such as Anguillosyllis, Amblyosyllis and Perkinsyllis) (Aguado et al. 2012). However, the available molecular information of most of syllids corresponds only to three genes, 18S, rrnL and cox1.

In order to investigate mitochondrial gene order evolution and possible divergence scenarios within Syllidae, we have analysed 5 new complete $\mathrm{mt}$ genomes of syllids using next generation sequencing techniques. These new $\mathrm{mt}$ genomes, together with $R$. multicaudata and T. cryptica, represent most of the main groups within the family: Anoplosyllinae, Eusyllinae, Autolytinae and Syllinae. Additionally, the data provided herein allow to perform phylogenetic analyses including less taxa than previous analyses (Aguado et al., 2007, 2012, $2015 \mathrm{a}, \mathrm{b})$, though much larger amount of data (15 genes and 12,100-13,200 bp). Results provide more evidence about phylogenetic relationships within Syllidae.

\section{Materials and methods}

\subsection{Taxa included}

Specimens of Eusyllis blomstrandi and Myrianida brachycephala were collected near Helgoland (Germany); Streptosyllis sp. was collected in Sylt (Germany); and Typosyllis antoni and Typosyllis sp. were obtained from bought live rock of the Indian Ocean kept in the aquarium in Leipzig (Germany). The two other syllids, Ramisyllis multicaudata and 
Trypanobia cryptica, as well as outgroup $\mathrm{mt}$ genomes, were downloaded from Genbank (Table 1).

\subsection{Genome sequencing}

Specimens were partly fixed in $95 \%$ ethanol for DNA sequencing and DNA was extracted from single individuals by using commercial kits. For M. brachycephala, E. blomstrandi and the two Typosyllis species Illumina sequencing, double index sequencing libraries with average insert sizes of around $300 \mathrm{bp}$ were prepared as previously described (Meyer and Kircher 2010; Kircher et al. 2012). The libraries were sequenced as either 100 or 140 bp paired-end runs on an Illumina Hi-Seq 2000. Base calling was performed with freelbis (Renaud et al. 2013), adaptor and primer sequences were removed using leeHom (Renaud et al. 2014), and reads with low complexity and false paired indices were discarded. Quality $\begin{array}{lllll}\text { control was checked } & \text { FastQC }\end{array}$ (http://www.bioinformatics.babraham.ac.uk/projects/fastqc/). Raw data of all libraries were trimmed by removing low quality reads. The quality of all sequences after trimming was checked using Trimmomatic v0.32 (Bolger et al. 2014). DNA extraction, genome amplification, library preparation and sequencing for Streptosyllis sp. followed the procedure described in Golombek et al. (2013). De novo assemblies were conducted with CLC Genomics Workbench 5.1 (CLC bio, Århus, Denmark) using default settings (Streptosyllis sp.) and with IDBA-UD (Peng et al. 2012), using an initial $k$-mer size of 21 , an iteration size of 10 and a maximum $k$-mer size of 91 (all other syllids). All sequence data were submitted to the National Centre for Biotechnology Information (NCBI) (Table 1). The coverage of mt genomes was estimated by mapping sequence reads back to the contig comprising the $\mathrm{mt}$ genome using BWA under default options (Li and Durbin 2009). Visual exploration of the coverage of all assemblies was performed with the program Tablet (Milne et al. 2013).

\subsection{Mitochondrial genome annotation and gene order analyses}

The mt genomes were annotated using the MITOS webserver (Bernt et al. 2013b) with the "Invertebrates" NCBI code for translation. This server also provided the secondary structure of tRNA's and rRNA's. All automatic annotations were finally manually curated. AT and GC skew were determined for the complete mt genomes according to the formula defined by 
Perna and Kocher (1995), AT skew $=(A-T) /(A+T)$ and $G C$ skew $=(G-C) /(G+C)$, where the letters stand for the number of the corresponding nucleotides in the sequences. Characterization of codon usage bias was calculated with the program DAMBE5 (Xia 2013).

We used CREx (Bernt et al. 2007) to conduct pairwise comparisons of the mitochondrial gene order. CREx determines the most parsimonious genome rearrangement scenario between the gene order of each pair of taxa including transpositions, reverse transpositions, reversals, and tandem-duplication-random-loss (tdrl) events. The analysis was performed applying the common intervals parameter for distance measurement. Two different analyses were performed, the first one including all the genes (protein coding genes, rRNA's and tRNA's), while in the second tRNA's were excluded, since they are usually more variable than other genes.

\subsection{Phylogenetic analyses}

Datasets of all mitochondrial protein-coding genes, together with $r r n L$ and $r r n S$ from the syllids and outgroups (Table 1) were constructed to perform phylogenetic analyses. Alignments of orthologous partitions were performed using the program Mafft (Katoh et al. 2002) with the default parameters for the protein coding genes and the iterative refinement method E-INS-i, and default gap open and extension values for $r r n L$ and $r$ rnS. Nucleotide alignments of protein coding genes were generated by back-translation for each gene using the software Translator X (Abascal et al. 2010). Ambiguously aligned and variable regions were recognized and excluded using the program Gblocks (Castresana 2000) with relaxed parameters (smaller final blocks, gap positions within the final blocks, and less strict flanking positions allowed). Concatenation of partitions for the combined data set was conducted with FASconCAT-G (Kück and Longo 2014). Several data sets were examined: 1. Alignments of nucleotides and $r r n L+r r n S ; 2$. Alignments of amino acids; 3 . Alignments of nucleotides and $r r n L+r r n S$ without ambiguous regions; 4. Alignments of amino acids without ambiguous regions.

Maximum Likelihood (ML) analyses were conducted using RAxML version 8.1.3 (Stamatakis 2014), with GTR+I+G model, as GTR is the only available nucleotide model in this program. For amino acids we chose the MtZoa $+G+F$ model of sequence evolution, which has been specifically designed for lophotrochozan mt genomes (Rota-Stabelli et al. 2009). Bootstrap 
support values were generated with a rapid bootstrapping algorithm (Stamatakis et al. 2008) for 1000 replicates in RAxML. Analysis of the alignments of nucleotides and $r r n L+r r n S$ without ambiguous regions was also performed through bayesian inference methods (BI). The program MRBAYES v. 3.2.6 (Huelsenbeck and Ronquist, 2001) was used to combine two independent runs of 1,000,000 generations each with three heated and one cold Monte Carlo Markov chain (MCMC), starting from default prior values and random trees and applying the $G T R+I+G$ model. Trees were sampled every 1,000 generations each. All parameters were unlinked, and rates were allowed to vary freely over partitions. After discarding 250 first trees as burn-in, trees from the stationary phase were combined to obtain a majority rule consensus and posterior node probabilities (Huelsenbeck and Ronquist, 2001).

\section{Results and discussion}

\subsection{Mitochondrial genomes}

BLAST-searches identified the complete mitochondrial genomes of all investigated syllids as a single contig. All $\mathrm{mt}$ genomes are highly covered by sequence reads: Myrianida brachycephala 164x, Eusyllis blomstrandi 158x, Typosyllis antoni 206x, Typosyllis sp. 222x, Streptosyllis sp. 119x. All mt genomes are deposited in Genbank and accession numbers can be found in Table 1. The complete mt genomes of Streptosyllis sp., E. blomstrandi and M. brachycephala are around 15,000 bp long (Table 2). The $\mathrm{mt}$ genomes of $T$. antoni and Typosyllis sp. are longer, with 16,902 and 16,241 bp, respectively. The mt genome size of other annelids usually varies between 15,000 and 16,000 bp (see Supplementary Table 1). The longest $\mathrm{mt}$ genomes are those of sylline taxa, including the two previously investigated syllids, Ramisyllis multicaudata and Trypanobia cryptica (15,748 bp and 16,630 bp, respectively) (Aguado et al. 2015a) (Table 2). The gene orders of the five new $\mathrm{mt}$ genomes are illustrated in Fig. 1.

The syllid genomes are AT-rich (around 70\%) (Table 2). In Streptosyllis sp., E. blomstrandi and M. brachycephala, the most common base is T (values around 40\%), while in T. antoni and Typosyllis sp. A and T are approximately equally frequent (34-35\%) and more common than $\mathrm{G}$ and $\mathrm{C}$ (Table 2). In R. multicaudata and T. cryptica, A is the most common base (34-36\%). In the mt genomes of Streptosyllis, E. blomstrandi, M. brachycephala and T. antoni, the AT 
skew is negative $(-0.18,-0.09,-0.1,-0.01$, respectively) (Table 2$)$. It is positive though very low in Typosyllis sp. (0.004). The GC skew is negative in E. blomstrandi, M. brachycephala, $T$. antoni and Typosyllis sp. $(-0.06,-0.21,-0.23,-0.24$, respectively), while it is positive in Streptosyllis sp. $(0,06)$ (Table 2). In R. multicaudata and T. cryptica, the AT skews are positive, while GC skews negative (Aguado et al. 2015a). In most studied annelids, the GC skew is usually more negative than the AT skew (Bleidorn et al. 2006; Zhong et al. 2008; Richter et al. 2015; Li et al. 2016; Patra et al. 2016).

For each of the five $\mathrm{mt}$ genomes sequenced in this study, all 13 protein coding genes, two rRNA's and the typical 22 tRNA's could be detected (Fig. 1, Supplementary Tables 2-6). Two genes in Streptosyllis sp. showed a reading frame shift due to the insertion of single bases (nad3, nad4L). These shifts were also supported by sequence reads mapped back to the mitochondrial contig. However, as during library preparation whole genome amplification was conducted for this species, this is likely a PCR artefact. Consequently, we manually curated this shifts using alignments from the other syllids as a reference. In $T$. antoni and Typosyllis sp. one additional gene was found, as the methionine tRNA (trnM) is duplicated (Supplementary Tables 5, 6). The two trnMs are located one after another (Fig. 1). The trnM has previously been also found duplicated in the $\mathrm{mt}$ genomes of Pista cristata Terebellides stroemi, and Pectinaria gouldi (Zhong et al. 2008; Zhong et al. 2011), Phascolosoma esculenta (Shen et al. 2009), and also in Chaetopterus variopedatus and Eurythoe complanata (Weigert et al. 2016). As in the case for most of annelids so far studied, except Owenia fusiformis and Magelona mirabilis (Weigert et al. 2016), all genes are transcribed from the same strand (referred to as plus-strand).

Start codons in the protein-coding genes are highly biased towards ATG (Supplementary Tables 2-6). Other start codons, such as ATA, ATT, AGA, TTG, and GTG, have been found in Streptosyllis sp., T. antoni and Typosyllis sp. The stop codons are mostly TAA and, in less amount TAG. Occasionally, some genes of Streptosyllis sp., T. antoni and Typosyllis sp. end in TA or simply T. These variations from the typical stop and start codons have been also found in R. multicaudata and T. cryptica (Aguado et al. 2015a), and incomplete stop codons are also present in other annelids (Bleidorn et al. 2006; Li et al. 2016). Interestingly, alternative start and stop codons only appear in those syllids with highly rearranged genomes (i.e. Streptosyllis sp. and the sylline species). There is also a codon usage bias in the investigated genomes (Supplementary Table 7). In general, NNA and NNT codons are the most common 
codon types, while NNG codons are the least used. In general, the syllids share with other annelids a similar pattern of codon usage bias (Jennings and Halanych 2005; Bleidorn et al. 2006; Zhong et al. 2008; Zhong et al. 2011; Patra et al. 2016).

The tRNA's mostly possess the common cloverleaf structure, with an acceptor arm, anticodon arm, TUC arm, DHU arm, and associated loop regions. The DHV stem is missing in the trnR of the five investigated mt genomes. The DHV stem is also missing in the trnS2 of Streptosyllis sp., T. antoni and Typosyllis sp., in the trnS1 of Streptosyllis sp. and Typosyllis sp., and in the trnC of Typosyllis sp.; while it is reduced in the trnS1 and trnS2 of $E$. blomstrandi and trnS1 of T. antoni. The TWC arm is missing in the trnH of Streptosyllis sp. In M. brachycephala, the trnS1 has the DHV arm modified as a large loop and it has one short additional arm between the anticodon and the TUC arm. Other syllids, such as $R$. multicaudata and T. cryptica also show trnS1 and trnS2 with a shortened DHV stem. The DHU arm, and less often the TUC arm, is also missing or reduced in the tRNA's of other annelids (Jennings and Halanych 2005; Bleidorn et al. 2006; Zhong et al. 2008; Mwinyi et al. 2009; Richter et al. 2015). The lengths of the ribosomal genes in the syllids are similar to each other, excepting in Streptosyllis sp., where they are shorter (rrnL: 587 bp, rrnS: 532 bp), especially comparing with the sylline. In E. blomstrandi the sizes of the rRNA's are: rrnL: 1000 bp, rrnS: 742 bp; in M. brachycephala, rrnL: 1011 bp, rrnS: 756 bp; in T. antoni, rrnL: 1000 bp, rrnS: $877 \mathrm{bp}$; and finally, in Typosyllis sp. the largest, rrnL: 1001 bp, rrnS: 904 bp (Supplementary Tables 2-6). The latter values are similar to R. multicaudata, rrnL: $1008 \mathrm{bp}$, rrnS: 787 bp; and T. cryptica, rrnL: 1007 bp, rrnS: 789 bp (Aguado et al. 2015a).

The non-coding regions present in the $\mathrm{mt}$ genomes vary considerably. In E. blomstrandi and M. brachycephala, most of genes are overlapping or separated by very short non-coding regions of few bp (Supplementary Tables 3, 4), except the non-coding region between the trnV and rrnL that are 136 bp and 135 bp, respectively. In contrast, Streptosyllis sp., T. antoni and Typosyllis sp., show several longer non-coding regions with sizes between 50 and $445 \mathrm{bp}$ (Supplementary Tables 2, 5, 6). Interestingly, BLAST searches did not recover any hints that these regions stem from tandem duplication random loss (tdrl) events (Moritz et al. 1987). In the five mt genomes, the longest non coding regions are AT rich and are suggested to be the putative control regions. The presence of non-coding regions of variable sizes through the 
mt genome has also been documented for other annelids (Jennings and Halanych 2005; Bleidorn et al. 2006; Weigert et al. 2016).

\subsection{Phylogenetic analyses}

The results obtained from nucleotide data sets (protein-coding genes and $r r n L+r r n S$ ), as well as those obtained when analyzing the amino acid data sets, widely agree in the topologies, independently of the exclusion of the ambiguous regions in the alignments. Results obtained through $\mathrm{ML}$ and $\mathrm{BI}$ are also congruent. Syllidae is always recovered as a monophyletic group, though the support values depend on the analysis. The bootstrap (BS) and posterior probability (PP) values are high (100\% and 1 respectively) in the analysis obtained from nucleotides excluding the ambiguous regions (Fig. 2), while low (75\%) or very low (39\%) in the analyses obtained from amino acids including the ambiguous regions or excluding them, respectively (Supplementary Figs. 1A-C).

Streptosyllis sp., a member of Anoplosyllinae, is part of Syllidae in all analyses. Usually Anoplosyllinae is the sister group to the rest of syllids or part of a basal polytomy (Fig. 2, Supplementary Figs. 1A, B). Only in the topology obtained when analyzing amino acids without ambiguous regions (Supplementary Fig. 1C), Streptosyllis sp. is sister to $M$. brachycephala, but the support value of this clade is considerably low (48\%). Eusyllis blomstrandi and M. brachycephala, members of Eusyllinae and Autolytinae, respectively, vary their positions as well depending on the analyses, but all the Syllinae are in a wellsupported monophyletic group (Fig. 2, Supplementary Figs. 1A-C). Within Syllinae, T. antoni and Typosyllis sp. always represent well-supported sister taxa, and R. multicaudata and T. cryptica are in a well-supported clade as well, except in the results from amino acids with ambiguous regions, where the relationships within Syllinae were not fully resolved (Supplementary Fig. 1B). In general, the topologies obtained when analyzing nucleotides are better resolved than those obtained from amino acids.

The results are in agreement with previous phylogenetic analyses (Aguado et al. 2007, 2012, 2015a, 2015b) which have been performed based on only three genes, one nuclear (18S) and two mitochondrial ( $r r n L$ and cox1), which all together were approximately $3000 \mathrm{bp}$. The herein performed phylogenetic analyses include 13 mitochondrial coding genes and two 
rRNA genes ( $r r n L$ and $r r n S)$, which sum approximately 12,100-13,200 bp, depending on each taxon. The obtained results also support the conclusions of Aguado and Bleidorn (2010), who explained that a different location of Anoplosyllinae, outside syllids, was an artifact due to the effect in the alignment of a hypervariable region in the nuclear gene $18 \mathrm{~S}$. In summary, all results considered suggest that the phylogenetic relationships of major clades within Syllidae are well established.

\subsection{Gene order}

The gene order within annelids had been considered as relatively conserved (e.g., Jennings and Halanych 2005; Vallès and Boore 2006; Zhong et al. 2008). However, Weigert et al. (2016) examined several basal branching terminals and demonstrated that the supposedly highly conserved mitochondrial gene order in Annelida is restricted to Pleistoannelida (which includes Errantia and Sedentaria), and likely represents the ground pattern of this group.

Within Syllidae, we found the Pleistoannelida ground pattern in two of the seven analyzed genomes: E. blomstrandi and M. brachycephala (members of Eusyllinae and Autolytinae, respectively) (Fig. 3). However, the gene order changes considerably in Streptosyllis sp. (Anoplosyllinae) and especially in the Syllinae. In Syllinae, the four terminals included, which represent the two main clades within this subfamily (R. multicaudata and T. cryptica on one hand, and T. antoni and Typosyllis sp. on the other) show two completely different gene arrangements (Figs. 1, 3).

The CREx analyses reveal possible scenarios for these two divergences from the common pattern. When compared with $P$. dumerilii (representing the pleistoannelid ground pattern), the gene order of Streptosyllis sp. might be the result of 2 transpositions and $3 \mathrm{tdrl}$ (including tRNA's), or only 2 transpositions (excluding tRNA's). The second deviation occurs in the Syllinae where the number of $\mathrm{tdrl}$ increases considerably, 4-5 tdrl when including the $t R N A^{\prime} s$, accompanied by several transpositions in most cases; or 1-3 tdrl and 2-3 transpositions when excluding the tRNA's. The high number of non-coding regions contributing to longer $\mathrm{mt}$ genomes in Syllinae when compared to other syllids (see Supplementary Tables 2-6 and Aguado et al. (2015a)) and many other annelids could be hypothesized as possible remnants of several tdrl events. However, BLAST searches identified no similarities with other regions within the respective $\mathrm{mt}$ genomes. 
Tables 3 and 4 summarize these results using similarity scores, where the higher the numbers the more similar are the compared gene orders. The highest values, independently of including or excluding the tRNA's from the gene order, correspond to comparisons between outgroups with E. blomstrandi and M. brachycephala and among themselves. These values are followed by Streptosyllis sp. with any of them, while the lowest values correspond to the relationships of the syllinae with the rest. Within Syllinae, two clear groups are also recovered: $R$. multicaudata and T. cryptica; and T. antoni and Typosyllis sp. The most dissimilar order to the ground pattern would be the one in T. antoni and Typosyllis sp.

Mitochondrial gene orders of Pleistoannelida could be more diverse than expected. This would be not surprising considering that only few terminals have been investigated and they have been used to represent highly diverse taxa (such as Phyllodocida and Eunicida, for instance) (Supplementary Table 1). Aguado et al. (2015a) noted that there seem to be constraints that maintain the conserved pattern; however, when these constraints are violated, many changes might be possible. The results shown herein are fitting with this notion and provide more information about the scenario of gene order evolution in syllids. Myrianida brachycephala (Autolytinae) and E. blomstrandi (Eusyllinae) show the putative ground pattern of the pleistoannelid mitochondrial gene order. This order independently changed considerably in Streptosyllis sp. (Anoplosyllinae) and all analyzed members of the Syllinae. The Syllinae is the most complex group within Syllidae, with still many difficult systematic issues to be resolved and biological features to be investigated. They are animals with complex life cycles involving the development of independent sexual units called stolons and branching body patterns as in $R$. multicaudata. The phylogenetic relationships reveal two clear lineages: the ribbon clade (as named by Aguado et al. (2015a)), including Ramisyllis and flattened syllids, and a large clade including mostly Typosyllis and Syllis spp. The four investigated sylline $\mathrm{mt}$ genomes do not show a clear common pattern and even closely related pairs of species (Typosyllis sp. and T. antoni; R. multicaudata and T. cryptica, respectively) show more evidence of gene re-arrangements as usually found across pleistoannelids at all. Obviously, mitochondrial gene order evolution is labile in Syllidae, underlying fewer constraints than in other annelids. This suggests that gene order analyses might be phylogenetically informative in this clade. However, we cannot provide any biological reason why the evolution of mitochondrial genomes is highly dynamic within this 
group. Diverse mitochondrial gene orders have also been found within tunicates, molluscs and brachiopods (lannelli et al. 2007; Rawlings et al. 2010; Stach et al. 2010; Yuan et al. 2012; Luo et al. 2015). In the latter taxon, mitochondrial genomes of the (putatively) same species (Lingula anatina) from different locations showed considerable differences (Luo et al. 2015). The authors speculate that maybe other mechanisms besides $\mathrm{tdrl}$ are responsible for the shuffling of gene orders. Instead, a transposition mechanism involving recombination with double-stranded break repair is hypothesized. This mechanism would be an example of intramolecular recombination, which among others has been already demonstrated for cnidarians (Brockman and McFadden 2012) and bird mitochondrial genomes (Sammler et al. 2011). In some studies the presence of so-called minicircles containing fragments of the mitochondrial genomes coincide with a largely rearranged gene order of the mitochondrium. The generation of these mini-circles is hypothesized as a step necessary for intramolecular recombination. By homologous recombination these minicircles are integrated back into the $\mathrm{mt}$ genome, thereby generating gene rearrangements. Future studies are necessary to investigate why mitochondrial gene order in some taxa is less constraint than in other and syllids seem to be a putative test case for this question.

\section{Acknowledgments}

This study is a contribution of the project "Macroevolutionary transitions in Syllidae" CGL2015-63593-P supported by the MINECO/FEDER, UE funds. MTA was supported by the "José Castillejo" fellow by MINECO (Ministerio de Economía y Competitividad, Spanish Government) for a research stay at the University of Leipzig (Germany). CB is supported by a "Ramón y Cajal" fellow by the MINECO, project no RYC-2014-15615. THS acknowledges support by the German Science Foundation (DFG STR-683/6-1, 6-2 and 8-1). This is a NHM Evolutionary Genomics Lab contribution. We are grateful to the crew from the Biological Station in Helgoland (Germany) for supporting the fieldtrip.

\section{Supplementary data}

Supplementary data associated with this article can be found, in the online version, at $x x x$ 


\section{References}

Abascal, F., R. Zardoya \& M. J. Telford, 2010. TranslatorX: multiple alignment of nucleotide sequences guided by amino acid translations. Nucleic Acids Research 38: W7-W13.

Aguado, M. T. \& C. Bleidorn, 2010. Conflicting signal within a single gene confounds syllid phylogeny (Syllidae, Annelida). Molecular Phylogenetics and Evolution 55: 1128-1138.

Aguado, M. T., A. Nygren \& M. E. Siddall, 2007. Phylogeny of Syllidae (Polychaeta) based on combined molecular analysis of nuclear and mitochondrial genes. Cladistics 23: $552-564$.

Aguado, M. T., G. San Martin \& M. E. Siddall, 2012. Systematics and evolution of syllids (Annelida, Syllidae). Cladistics 28: 234-250.

Aguado, M. T., C. J. Glasby, P. Schroeder, A. Weigert \& C. Bleidorn, 2015a. The making of a branching annelid: an analysis of complete mitochondrial genome and ribosomal data of Ramisyllis multicaudata. Scientific Reports srep12072.

Aguado, M. T., C. Helm, M. Weidhase \& C. Bleidorn, 2015b. Description of a new syllid species as a model for evolutionary research of reproduction and regeneration in annelids. Organisms Diversity \& Evolution 15: 1-21.

Bernt, M., D. Merkle, K. Ramsch, G. Fritzsch, M. Perseke, D. Bernhard, M. Schlegel, P. F. Stadler \& M. Middendorf, 2007. CREx: inferring genomic rearrangements based on common intervals. Bioinformatics 23: 2957-2958.

Bernt, M., C. Bleidorn, A. Braband, J. Dambach, A. Donath, G. Fritzsch, A. Golombek, H. Hadrys, F. Juhling, K. Meusemann, M. Middendorf, B. Misof, M. Perseke, L. Podsiadlowski, B. von Reumont, B. Schierwater, M. Schlegel, M. Schrodl, S. Simon, P. F. Stadler, I. Stoger \& T. H. Struck, 2013a. A comprehensive analysis of bilaterian mitochondrial genomes and phylogeny. Mol Phylogenet Evol 69: 35264.

Bernt, M., A. Donath, F. Juehling, F. Externbrink, C. Florentz, G. Fritzsch, J. Puetz, M. Middendorf \& P. F. Stadler, 2013b. MITOS: Improved de novo metazoan mitochondrial genome annotation. Molecular Phylogenetics and Evolution 69: 313-319.

Bleidorn, C., L. Podsiadlowski \& T. Bartolomaeus, 2006. The complete mitochondrial genome of the orbiniid polychaete Orbinia latreillii (Annelida, Orbiniidae) - A novel gene order for Annelida and implications for annelid phylogeny. Gene 370: 96-103.

Bolger, A. M., M. Lohse \& B. Usadel, 2014. Trimmomatic: a flexible trimmer for Illumina sequence data. Bioinformatics 30: 2114-2120.

Boore, J. L., 1999. Animal mitochondrial genomes. Nucleic Acids Research 27: 17671780.

Boore, J. L., 2004. Complete mitochondrial genome sequence of Urechis caupo, a representative of the phylum Echiura. Bmc Genomics 5: 67.

Brockman, S. A. \& C. S. McFadden, 2012. The mitochondrial genome of Paraminabea aldersladei (Cnidaria: Anthozoa: Octocorallia) supports intramolecular recombination as the primary mechanism of gene rearrangement in octocoral mitochondrial genomes. Genome Biology and Evolution 4: 994-1006.

Castresana, J., 2000. Selection of Conserved Blocks from Multiple Alignments for Their Use in Phylogenetic Analysis. Molecular Biology and Evolution 17: 540-552. 
Golombek, A., S. Tobergte, M. P. Nesnidal, G. Purschke \& T. H. Struck, 2013. Mitochondrial genomes to the rescue - Diurodrilidae in the myzostomid trap. Molecular Phylogenetics and Evolution 68: 312-326.

Hints, O. \& M. E. Eriksson, 2007. Diversification and biogeography of scolecodontbearing polychaetes in the Ordovician. Palaeogeography, Palaeoclimatology, Palaeoecology 245: 95-114.

Huelsenbeck, J. P. \& F. Ronquist, 2001. MRBAYES: Bayesian inference of phylogenetic trees. Bioinformatics 17: 754-755.

Iannelli, F., F. Griggio, G. Pesole \& C. Gissi, 2007. The mitochondrial genome of Phallusia mammillata and Phallusia fumigata (Tunicata, Ascidiacea): high genome plasticity at intra-genus level. Bmc Evolutionary Biology 7: 155.

Jennings, R. M. \& K. M. Halanych, 2005. Mitochondrial Genomes of Clymenella torquata (Maldanidae) and Riftia pachyptila (Siboglinidae): Evidence for Conserved Gene Order in Annelida. Molecular Biology and Evolution 22: 210-222.

Katoh, K., K. Misawa, K. i. Kuma \& T. Miyata, 2002. MAFFT: a novel method for rapid multiple sequence alignment based on fast Fourier transform. Nucleic Acids Research 30: 3059-3066.

Kircher, M., S. Sawyer \& M. Meyer, 2012. Double indexing overcomes inaccuracies in multiplex sequencing on the Illumina platform. Nucleic Acids Research 40: e3.

Kück, P. \& G. C. Longo, 2014. FASconCAT-G: extensive functions for multiple sequence alignment preparations concerning phylogenetic studies. Frontiers in Zoology 11: 1-8.

Li, H. \& R. Durbin, 2009. Fast and accurate short read alignment with Burrows-Wheeler transform. Bioinformatics 25: 1754 - 1760.

Li, Y., K. M. Kocot, C. Schander, S. R. Santos, D. J. Thornhill \& K. M. Halanych, 2015. Mitogenomics reveals phylogeny and repeated motifs in control regions of the deep-sea family Siboglinidae (Annelida). Molecular Phylogenetics and Evolution 85: 221-229.

Li, S., Y. Chen, M. Zhang, X. Bao, Y. Li, W. Teng, Z. Liu, C. Fu, Q. Wang \& W. Liu, 2016. Complete mitochondrial genome of the marine polychaete, Marphysa sanguinea (Polychaeta, Eunicida). Mitochondrial DNA Part A 27: 42-43.

Licher, F. 1999, Revision of der Gattung Typosyllis Langerhans, 1879 (Polychaeta: Syllidae). Morphologie, Taxonomie und Phylogenie. Abhl. Senckenberg. Naturforsch. Gesells. 551: 1-336.

Luo, Y.-J., N. Satoh \& K. Endo, 2015. Mitochondrial gene order variation in the brachiopod Lingula anatina and its implications for mitochondrial evolution in lophotrochozoans. Marine Genomics 24, Part 1: 31-40.

Meyer, M. \& M. Kircher, 2010. Illumina sequencing library preparation for highly multiplexed target capture and sequencing. Cold Spring Harbor Protocols 2010: pdb.prot5448-.

Milne, I., G. Stephen, M. Bayer, P. J. A. Cock, L. Pritchard, L. Cardle, P. D. Shaw \& D. Marshall, 2013. Using Tablet for visual exploration of second-generation sequencing data. Briefings in Bioinformatics 14: 193-202.

Moritz, C., T. E. Dowling \& W. M. Brown, 1987. Evolution of animal mitochondrial DNA: Relevance for population biology and systematics. Annual Review of Ecology and Systematics 18: 269-292.

Mwinyi, A., A. Meyer, C. Bleidorn, B. Lieb, T. Bartolomaeus \& L. Podsiadlowski, 2009. Mitochondrial genome sequence and gene order of Sipunculus nudus give additional support for an inclusion of Sipuncula into Annelida. Bmc Genomics 10: 27. 
Nygren, A, 1999. Phylogeny and reproduction in Syllidae (Polychaeta). Zool. J. Linn. Soc. 126: 365-386.

Nygren, A, 2004. Revision of Autolytinae (Syllidae: Polychaeta). Zootaxa 680: 1-314.

Nygren, A. \& P. Sundberg, 2003. Phylogeny and evolution of reproductive modes in Autolytinae (Syllidae, Annelida). Mol. Phyl. Evol. 29: 235-249.

Patra, A. K., Y. M. Kwon, S. G. Kang, Y. Fujiwara \& S.-J. Kim, 2016. The complete mitochondrial genome sequence of the tubeworm Lamellibrachia satsuma and structural conservation in the mitochondrial genome control regions of Order Sabellida. Marine Genomics 26: 63-71.

Peng, Y., H. C. M. Leung, S. M. Yiu \& F. Y. L. Chin, 2012. IDBA-UD: a de novo assembler for single-cell and metagenomic sequencing data with highly uneven depth. Bioinformatics 28: 1420-1428.

Perna, N. \& T. Kocher, 1995. Patterns of nucleotide composition at fourfold degenerate sites of animal mitochondrial genomes. Journal of Molecular Evolution 41: 353358.

Rawlings, T. A., M. J. MacInnis, R. Bieler, J. L. Boore \& T. M. Collins, 2010. Sessile snails, dynamic genomes: gene rearrangements within the mitochondrial genome of a family of caenogastropod molluscs. Bmc Genomics 11: 440.

Renaud, G., M. Kircher, U. Stenzel \& J. Kelso, 2013. freeIbis: an efficient basecaller with calibrated quality scores for Illumina sequencers. Bioinformatics 29: 1208-1209.

Renaud, G., U. Stenzel \& J. Kelso, 2014. leeHom: adaptor trimming and merging for Illumina sequencing reads. Nucleic Acids Research 42: e141.

Richter, S., F. Schwarz, L. Hering, M. Böggemann \& C. Bleidorn, 2015. The utility of genome skimming for phylogenomic analyses as demonstrated for glycerid relationships (Annelida, Glyceridae). Genome Biology and Evolution 7: 34433462.

Rota-Stabelli, O., Z. Yang \& M. J. Telford, 2009. MtZoa: A general mitochondrial amino acid substitutions model for animal evolutionary studies. Molecular Phylogenetics and Evolution 52: 268-272.

Sammler, S., C. Bleidorn \& R. Tiedemann, 2011. Full mitochondrial genome sequences of two endemic Philippine hornbill species (Aves: Bucerotidae) provide evidence for pervasive mitochondrial DNA recombination. Bmc Genomics 12: 35.

Shen, X., X. Ma, J. Ren \& F. Zhao, 2009. A close phylogenetic relationship between Sipuncula and Annelida evidenced from the complete mitochondrial genome sequence of Phascolosoma esculenta. Bmc Genomics 10: 1-11.

Stach, T., A. Braband \& L. Podsiadlowski, 2010. Erosion of phylogenetic signal in tunicate mitochondrial genomes on different levels of analysis. Molecular Phylogenetics and Evolution 55: 860-870.

Stamatakis, A., 2014. RAxML version 8: a tool for phylogenetic analysis and post-analysis of large phylogenies. Bioinformatics 30: 1312-1313.

Stamatakis, A., P. Hoover \& J. Rougemont, 2008. A Rapid Bootstrap Algorithm for the RAxML Web Servers. Systematic Biology 57: 758-771.

Struck, T. H., 2011. Direction of evolution within Annelida and the definition of Pleistoannelida. Journal of Zoological Systematics and Evolutionary Research 49: 340-345.

Vallès, Y. \& J. L. Boore, 2006. Lophotrochozoan mitochondrial genomes. Integrative and Comparative Biology 46: 544-557.

Weigert, A. \& C. Bleidorn, 2016. Current status of annelid phylogeny. Organisms Diversity \& Evolution: 1-18. 
Weigert, A., A. Golombek, M. Gerth, F. Schwarz, T. H. Struck \& C. Bleidorn, 2016. Evolution of mitochondrial gene order in Annelida. Molecular Phylogenetics and Evolution 94: 196-206.

Wu, Z. G., X. Shen, M. A. Sun, J. F. Ren, Y. J. Wang, Y. L. Huang \& B. Liu, 2009. Phylogenetic analyses of complete mitochondrial genome of Urechis unicinctus (Echiura) support that echiurans are derived annelids. Molecular Phylogenetics and Evolution 52: 558-562.

Xia, X., 2013. DAMBE5: A comprehensive software package for data analysis in molecular biology and evolution. Molecular Biology and Evolution 30: 17201728.

Yuan, Y., Q. Li, H. Yu \& L. Kong, 2012. The complete mitochondrial genomes of six heterodont bivalves (Tellinoidea and Solenoidea): Variable gene arrangements and phylogenetic implications. Plos One 7: e32353.

Zhang, L., P. Sechi, M. Yuan, J. Jiang, Y. Dong \& J. Qiu, 2016. Fifteen new earthworm mitogenomes shed new light on phylogeny within the Pheretima complex. Scientific Reports 6: 20096.

Zhong, M., B. Hansen, M. P. Nesnidal, A. Golombek, K. M. Halanych \& T. H. Struck, 2011. Detecting the symplesiomorphy trap: A multigene phylogenetic analysis for terebelliform annelids. Bmc Evolutionary Biology 11: 369.

Zhong, M., T. H. Struck \& K. M. Halanych, 2008. Phylogenetic information from three mitochondrial genomes of Terebelliformia (Annelida) worms and duplication of the methionine tRNA. Gene 416: 11-21. 


\section{Figure legends}

Figure 1. Mitochondrial genomes from Syllidae. Form up to down: Streptosyllis sp., Eusyllis blomstrandi, Myrianida brachycephala, Ramisyllis multicaudata, Trypanobia cryptica; Typosyllis antoni and Typosyllis sp. Ramisyllis multicaudata and T. cryptica after Aguado et al. (2015a).

Figure 2. Maximum likelihood tree obtained when analyzing nucleotides from protein coding genes and $r r n L$ and $r r n S$, ambiguous regions excluded from all the genes. Bootstrap support values are above nodes. Poterior probability values from the equivalent topology obtained through a BI analysis are below nodes. Picture of Typosyllis sp.

Figure 3. Gene order in Syllidae. Mitochondrial genomes represented without tRNA's. The phylogenetic relationships are after Aguado et al. (2015a). * indicate well supported clades. Gene order in Pleistoannelida after Weigert et al. (2016). 
Table 1. Terminals used in the analyses and GenBank accession numbers

\begin{tabular}{|l|l|l|}
\hline Taxon & Family & Acc code \\
\hline Nephtys sp. & Nephtyidae & EU293739 \\
\hline Glycera capitata & Glyceridae & KT989320 \\
\hline Platynereis dumerilii & Nereididae & AF178678 \\
\hline Streptosyllis sp. & Syllidae; Anoplosyllinae & KX752422 \\
\hline Eusyllis blomstrandi & Syllidae; Eusyllinae & KX752423 \\
\hline Myrianida brachycephala & Syllidae; Autolytinae & KX752424 \\
\hline Ramisyllis multicaudata & Syllidae; Syllinae & KR534502 \\
\hline Trypanobia cryptica & Syllidae; Syllinae & KR534503 \\
\hline Typosyllis antoni & Syllidae; Syllinae & KX752426 \\
\hline Typosyllis sp. & Syllidae; Syllinae & KX752425 \\
\hline
\end{tabular}


Table 2. Mitochondrial genome length, nucleotide contents, and nucleotide skew. Ramisyllis multicaudata and T. cryptica after Aguado et al. (2015a).

\begin{tabular}{|l|l|l|l|l|l|l|l|l|l|}
\hline & $\begin{array}{l}\text { Mt genome } \\
\text { length (bp) }\end{array}$ & $A$ & $C$ & $G$ & $T$ & $G C$ & $A T$ & $\begin{array}{l}\text { GC } \\
\text { skew }\end{array}$ & $\begin{array}{l}A T \\
\text { skew }\end{array}$ \\
\hline Streptosyllis sp. & 14983 & $31 \%$ & $12 \%$ & $14 \%$ & $43 \%$ & $26 \%$ & $74 \%$ & 0.006 & -0.18 \\
\hline $\begin{array}{l}\text { Eusyllis } \\
\text { blomstrandi }\end{array}$ & 14712 & $32 \%$ & $15 \%$ & $14 \%$ & $39 \%$ & $29 \%$ & $71 \%$ & -0.006 & -0.09 \\
\hline $\begin{array}{l}\text { Myrianida } \\
\text { brachycephala }\end{array}$ & 15032 & $31 \%$ & $19 \%$ & $12 \%$ & $38 \%$ & $31 \%$ & $69 \%$ & -0.021 & -0.01 \\
\hline $\begin{array}{l}\text { Typosyllis } \\
\text { antoni }\end{array}$ & 16902 & $35 \%$ & $18 \%$ & $11 \%$ & $36 \%$ & $29 \%$ & $71 \%$ & -0.023 & -0.001 \\
\hline Typosyllis sp. & 16241 & $34 \%$ & $20 \%$ & $13 \%$ & $33 \%$ & $33 \%$ & $67 \%$ & -0.024 & 0.004 \\
\hline $\begin{array}{l}\text { Ramisyllis } \\
\text { multicaudata }\end{array}$ & 15748 & $34 \%$ & $22 \%$ & $11 \%$ & $33 \%$ & $33 \%$ & $67 \%$ & -0.031 & 0.02 \\
\hline $\begin{array}{l}\text { Trypanobia } \\
\text { cryptica }\end{array}$ & 16630 & $36 \%$ & $20 \%$ & $11 \%$ & $33 \%$ & $31 \%$ & $69 \%$ & -0.029 & 0.04 \\
\hline
\end{tabular}


Table 3. Matrix of gene order distance measure obtained from CREx analysis. tRNA's included. The highest the numbers the more similar are the compared gene orders.

\begin{tabular}{|l|l|l|l|l|l|l|l|l|l|l|}
\hline & $N$ & $G$ & $P$ & $S$ & $E$ & $M$ & $R$ & Try & Tan & Typo \\
\hline Nephtys sp. & 1326 & 1256 & 354 & 38 & 452 & 264 & 2 & 2 & 4 & 2 \\
\hline Glycera capittata & 1256 & 1326 & 376 & 38 & 450 & 262 & 2 & 4 & 4 & 2 \\
\hline Platynereis dumerilii & 354 & 376 & 1326 & 34 & 254 & 120 & 2 & 4 & 2 & 2 \\
\hline Streptosyllis sp. & 38 & 38 & 34 & 1326 & 40 & 38 & 12 & 8 & 4 & 6 \\
\hline Eusyllis blomstrandi & 452 & 450 & 254 & 40 & 1326 & 396 & 4 & 4 & 2 & 4 \\
\hline M. brachycephala & 264 & 262 & 120 & 38 & 396 & 1326 & 4 & 4 & 2 & 2 \\
\hline R. multicaudata & 2 & 2 & 2 & 12 & 4 & 4 & 1326 & 134 & 8 & 6 \\
\hline Trypanobia cryptica & 2 & 4 & 4 & 8 & 4 & 4 & 134 & 1326 & 14 & 12 \\
\hline Typosyllis antoni & 4 & 4 & 2 & 4 & 2 & 2 & 8 & 14 & 1326 & 674 \\
\hline Typosyllis sp. & 2 & 2 & 2 & 6 & 4 & 2 & 6 & 12 & 674 & 1326 \\
\hline
\end{tabular}


Table 4. Matrix of gene order distance measure obtained from CREx analysis tRNA's excluded. The highest the numbers the more similar are the compared gene orders.

\begin{tabular}{|l|l|l|l|l|l|l|l|l|l|l|}
\hline & $N$ & $G$ & $P$ & $S$ & $E$ & $M$ & $R$ & Try & Tan & Typo \\
\hline Nephtys sp. & 204 & 204 & 204 & 54 & 204 & 204 & 18 & 16 & 6 & 6 \\
\hline Glycera capittata & 204 & 204 & 204 & 54 & 204 & 204 & 18 & 16 & 6 & 6 \\
\hline Platynereis dumerilii & 204 & 204 & 204 & 54 & 204 & 204 & 18 & 16 & 6 & 6 \\
\hline Streptosyllis sp. & 54 & 54 & 54 & 204 & 54 & 54 & 12 & 12 & 4 & 4 \\
\hline Eusyllis blomstrandi & 204 & 204 & 204 & 54 & 204 & 204 & 18 & 16 & 6 & 6 \\
\hline M. brachycephala & 204 & 204 & 204 & 54 & 204 & 204 & 18 & 16 & 6 & 6 \\
\hline R. multicaudata & 18 & 18 & 18 & 12 & 18 & 18 & 204 & 154 & 2 & 2 \\
\hline Trypanobia cryptica & 16 & 16 & 16 & 12 & 16 & 16 & 154 & 204 & 2 & 2 \\
\hline Typosyllis antoni & 6 & 6 & 6 & 4 & 6 & 6 & 2 & 2 & 204 & 204 \\
\hline Typosyllis sp. & 6 & 6 & 6 & 4 & 6 & 6 & 2 & 2 & 204 & 204 \\
\hline
\end{tabular}




\section{mt genomes in Syllidae}

Streptosyllis sp.

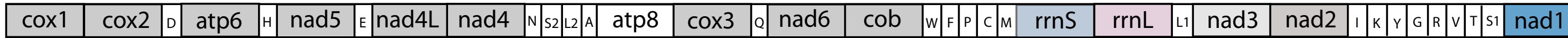

Eusyllis blomstrandi

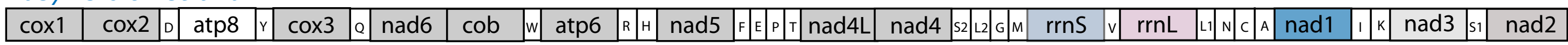

Myrianida brachycephala

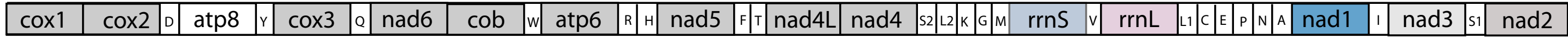

Ramisyllis multicaudata

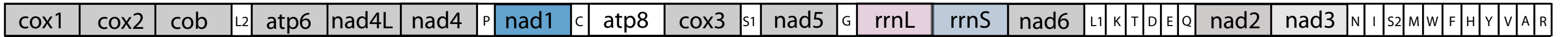

Trypanobia cryptica

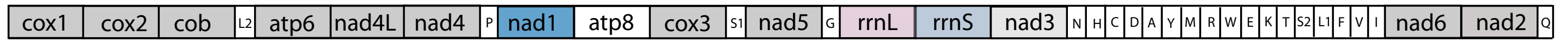

Typosyllis antoni

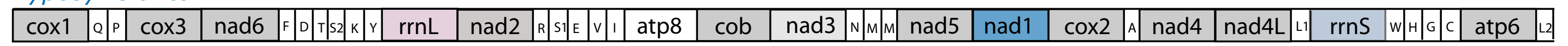

Typosyllis sp.

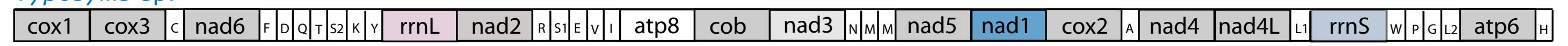



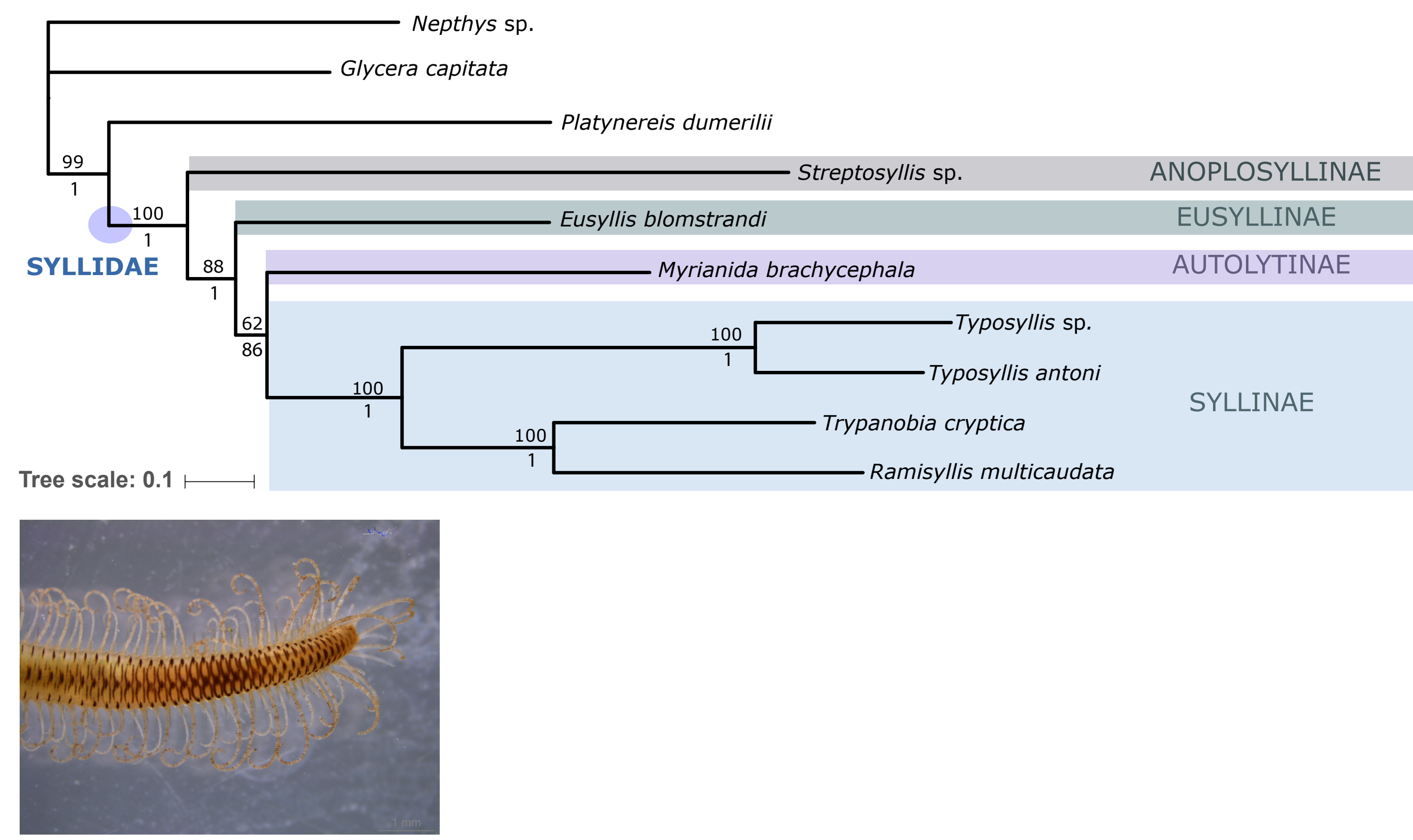
PLEISTOANNELIDA

\begin{tabular}{|l|l|l|l|l|l|l|l|l|l|l|l|l|l|l|}
\hline cox1 & cox2 & atp8 & cox3 & nad6 & cob & atp6 & nad5 & nad4L & nad4 & rrnS & rrnL & nad1 & nad3 & nad2 \\
\hline
\end{tabular}

\section{SYLLIDAE}

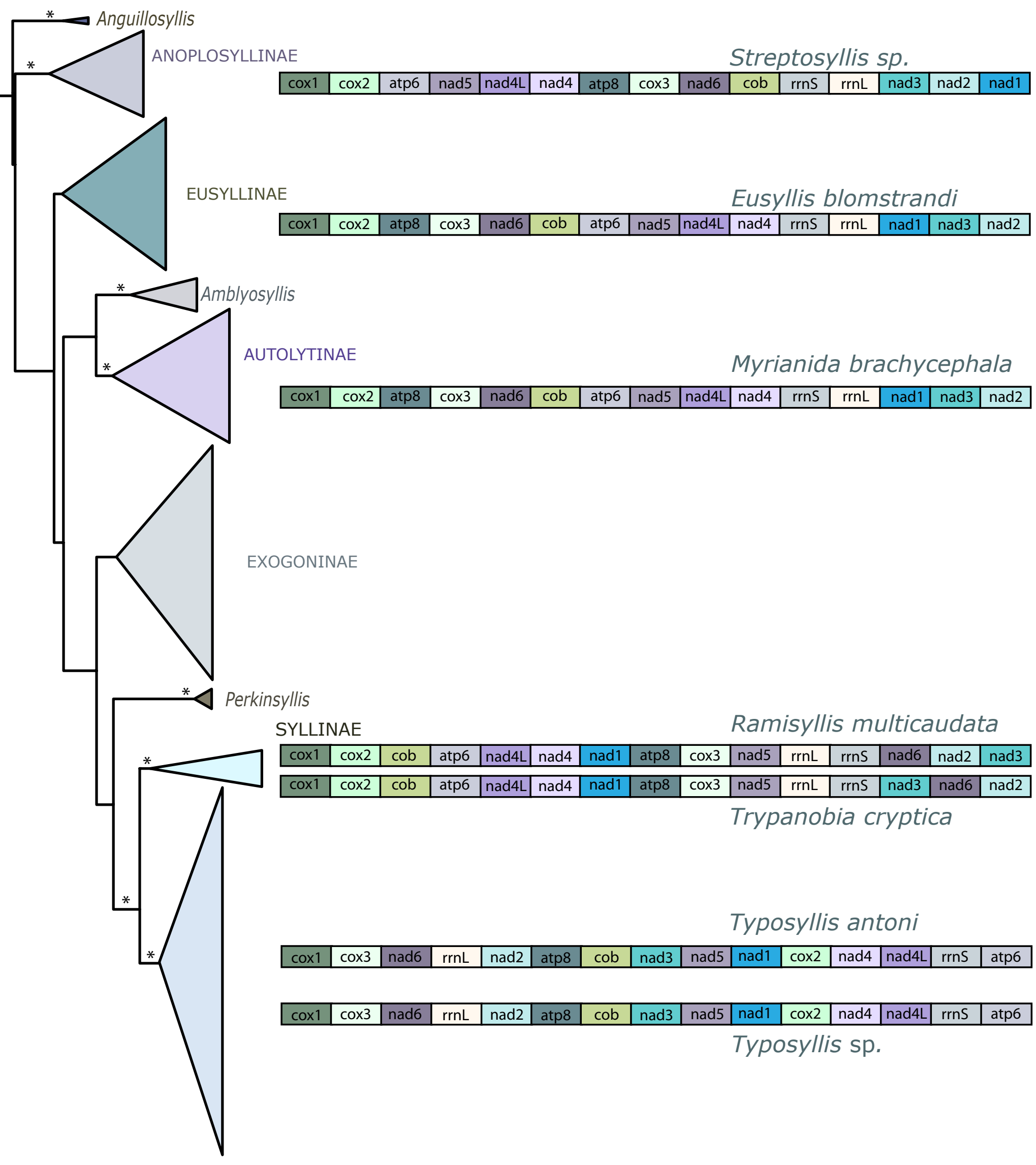


Supplementary material for on-line publication only
Click here to download Supplementary material for

Click here to download Supplementary material for on-line publication only: Supplementary material.docx

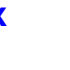

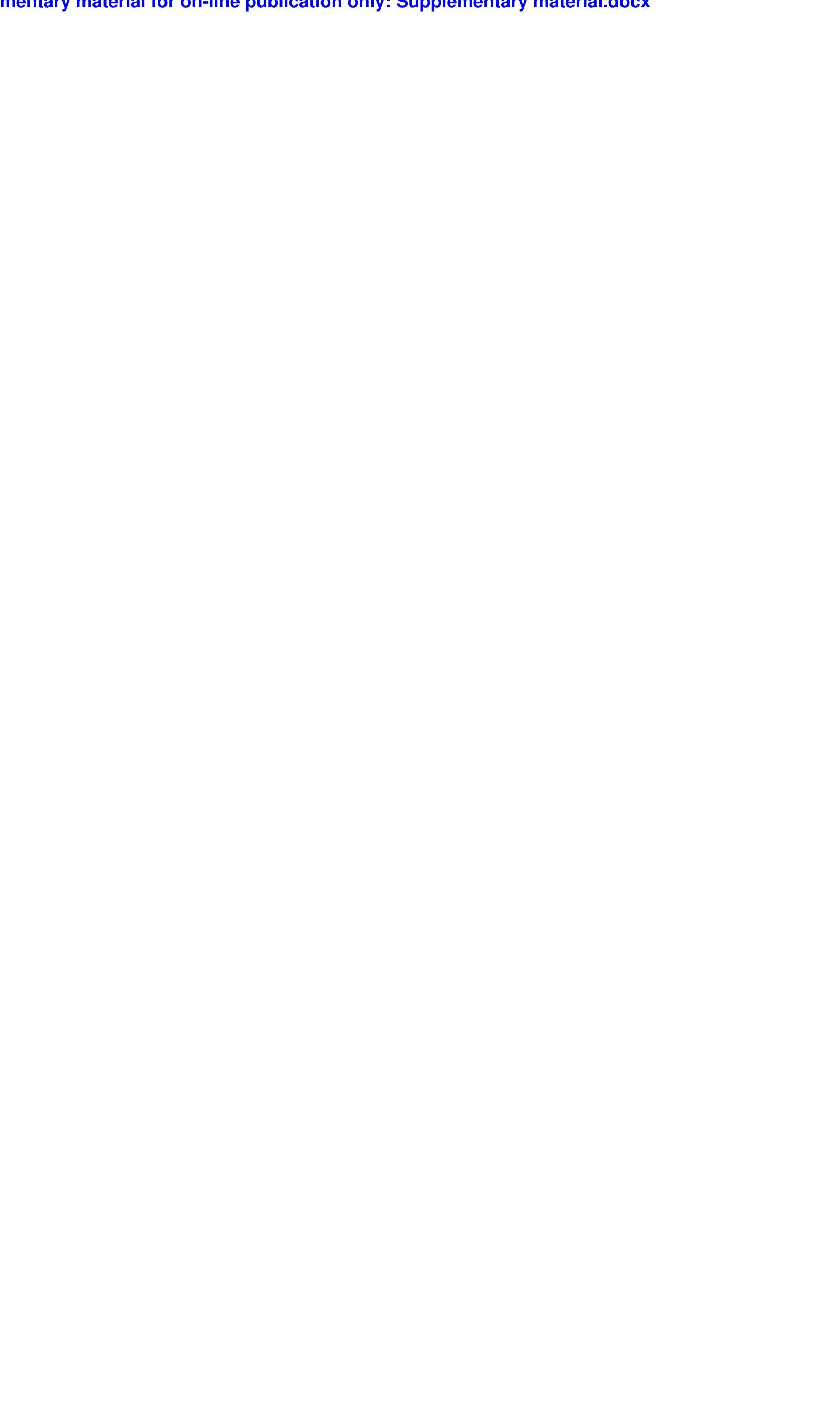

